\title{
MEANINGFUL AND CO-MEANINGFUL SEQUENCES
}

\section{G. J. O. JAMESON}

Abstract. Two versions of the concept "meaningful" are distinguished, "strictly" and "power" meaningful. By establishing the converse of a theorem of Bennett, a full characterisation of strictly meaningful sequences is given. A dual concept "co-meaningful" is introduced (again in two versions), and an analogous characterisation is obtained.

Mathematics subject classification (2010): 26D15, 26 A51.

Keywords and phrases: Monotonic, average, convex, meaningful.

\section{REFERENCES}

[1] Shoshana Abramovich, Graham Jameson and Gord Sinnamon, Inequalities for averages of convex and superquadratic functions, J. Ineq. Pure Appl. Math. 5 (2004), issue 4, article 91 (electronic).

[2] Grahame Bennett, Meaningful sequences, Houston J. Math. 33 (2007), 555-580.

[3] Grahame Bennett, Meaningful sequences and the theory of majorization, Houston J. Math. 35 (2009), 573-589.

[4] Grahame Bennett and Graham Jameson, Monotonic averages of convex functions, J. Math. Anal. Appl. 252 (2000), 410-430.

[5] G. J. O. Jameson, Monotonicity of weighted averages of convex functions, Math. Ineq. Appl. 23 (2020), 425-432. 